\title{
Imagen térmica y sensores de termopares para estimar el índice de estrés hídrico del cultivo de arroz bajo riego por goteo
}

\author{
Thermal imaging and thermocouple sensors for estimating water stress \\ index of rice cultivation under drip irrigation \\ Moisés Rodrigo Durán Gómez ; Lía Ramos Fernández²*; \\ Lisette Altamirano Gutiérrez ; José Arapa Quispe ${ }^{2}$
}

\section{RESUMEN}

El incremento de la evapotranspiración debido al calentamiento global del planeta hace que la permanencia en el tiempo del cultivo de arroz se vea amenazada por la alta demanda de agua que implica su producción. Por ello, este estudio tiene como objetivo estimar el índice de estrés hídrico foliar (Crop Water Stress Index - CWSI) a partir del procesamiento de imágenes térmicas obtenidas por sensores remotos, como herramienta para pasar de una escala de planta (dosel) a una mayor escala. La investigación se realizó en La Molina, Perú, en el periodo de otoño-invierno del 2017 (febrero-agosto), en el cultivo de arroz variedad IR 43 bajo riego por goteo. Se colectó información de la temperatura del dosel medida con una cámara térmica FLIR ajustada con información de termopares, y se correlacionó con información de humedad volumétrica del suelo medida con sensores FDR. El CWSI se obtuvo a partir de la temperatura foliar ajustada a las condiciones atmosféricas, la temperatura seca que representa la mínima transpiración (estomas cerrados) y la temperatura húmeda que representa la máxima transpiración (estomas totalmente abiertos). En la fase reproductiva y de maduración del cultivo se determinó que la temperatura húmeda fue de $15,2^{\circ} \mathrm{C}$ y $15,4^{\circ} \mathrm{C}$ y la temperatura seca de $33,7^{\circ} \mathrm{C}$ y $36^{\circ} \mathrm{C}$, respectivamente. Finalmente se obtuvo una correlación significativa de Pearson de $-0,522$ entre el CWSI y la humedad volumétrica del suelo, para un nivel de significancia del $5 \%$, a $0,3 \mathrm{~m}$ de profundidad del suelo. Se recomienda monitorear variables fisiológicas del cultivo para viabilizar el uso del CWSI e implementar calendarios de riego óptimos y, por lo tanto, una reducción en el consumo del agua.

Palabras clave: arroz, estrés hídrico, imágenes térmicas, termopares, riego por goteo.

\begin{abstract}
Given the high demand for water, the increase in evapotranspiration as a result of global warming of the planet threatens the sustainability of rice cultivation. This study aimed to estimate the foliar water stress index (Crop Water Stress Index-CWSI) from processing of thermal images obtained by remote sensors, as a tool for transiting from a plant scale (canopy) to a larger scale. The study was conducted at La Molina, Peru during the autumn-winter period (February-August, 2017) of cultivation of International Rice 43 variety under drip irrigation. Information regarding temperature of canopy was obtained using a FLIR thermal camera adjusted with information from thermocouples and correlated with volumetric soil moisture information measured with frequency domain reflectometry sensors. The CWSI was obtained from the foliar temperature adjusted to atmospheric conditions, such that dry temperature represents minimum transpiration (stomata closed) and wet temperature represents maximum transpiration (fully open stomata). In the reproductive and maturation phase of the crop, it was recorded that humid temperature was $15.2{ }^{\circ} \mathrm{C}$ and $15.4{ }^{\circ} \mathrm{C}$ and dry temperature was $33.7^{\circ} \mathrm{C}$ and $36^{\circ} \mathrm{C}$, respectively. A significant Pearson correlation coefficient of -0.522 was obtained between CWSI and volumetric soil moisture at a significance level of $5 \%$ at $0.3 \mathrm{~m}$ of soil depth. It is therefore recommended that CWSI should be utilised during the monitoring of crop physiological variables. In addition, more optimal irrigation schedule and reduction in water consumption should be implemented.
\end{abstract}

Keywords: rice, water stress, thermal imaging, thermocouples, drip irrigation.

\footnotetext{
1 Área Experimental de Riego, UNALM, Av. La Molina s/n La Molina, Lima, Perú.

2 Departamento de Recursos Hídricos, UNALM, Av. La Molina s/n La Molina, Lima, Perú.

* Autor por correspondencia: liarf@lamolina.edu.pe
}

Fecha de Recepción: 15 de Octubre, 2020.

Fecha de Aceptación: 30 de Diciembre, 2020. 


\section{Introducción}

La población mundial está creciendo a un ritmo alarmante y la demanda de agua dulce va en aumento (Ved Parkash and Sukhbir Singh, 2020). Cubrir esta demanda de agua es esencial para la supervivencia humana, el mantenimiento de la ecología y el desarrollo social (Pedro-Monzonís et al., 2015). Sin embargo, la escasez de agua dulce en el planeta genera amenazas a la seguridad alimentaria y al desarrollo sostenible en algunas partes del mundo. Por tanto, el uso eficiente y la conservación del agua es necesario para aumentar la producción de alimentos y al mismo tiempo prevenir la escasez del recurso hídrico (Abiodun et al., 2020). Además, los cambios ambientales se perciben como un riesgo sistémico global (Mekonnen et al., 2016) y tienen un impacto en la cantidad y calidad de los cultivos de mayor demanda, entre ellos, el arroz (Boonwichai et al., 2019), limitando su producción. Frente a esta situación, existen nuevas estrategias para optimizar el consumo de agua (Poblete, Ortega-Farías and Ryu, 2018). Es así como el riego mediante alternancia de humedecimiento y secado, definido como un régimen que reduce deliberadamente el agua de irrigación aplicado en etapas específicas del cultivo, puede ser una forma de lograr una mayor producción por unidad de agua consumida (Han et al., 2018).

El monitoreo del déficit hídrico en el cultivo es la base para la programación del riego, influenciado por el potencial hídrico del cultivo. Sin embargo, se necesita un monitoreo casi en tiempo real para reaccionar ante eventos extremos de acuerdo con las condiciones climáticas cambiantes (Weiss et al., 2020), además de la información de la respuesta de los cultivos al estrés hídrico para lograr el mejor equilibrio entre el uso eficiente del agua (UEA) y el rendimiento del cultivo (Geerts and Raes, 2009). Al respecto, los índices basados en el estado hídrico del suelo, el potencial hídrico del cultivo y los parámetros fisiológicos resultan útiles para la gestión del riego (Jones, 2018; Silva et al., 2007). Los índices basados en la temperatura del dosel son los de amplio uso en el diagnóstico del déficit de agua del cultivo como un método alternativo para la determinación del potencial hídrico (Bellvert et al., 2016). El cierre estomático reduce la transpiración y, por lo tanto, la velocidad de enfriamiento por evapotranspiración, lo cual ocasiona un aumento de la temperatura foliar y con ello el estrés hídrico de la planta (Maes et al., 2012). Para el estudio de estos síntomas del cultivo se sugiere el uso del índice de estrés hídrico foliar o Crop Water Stress Index, CWSI (Jones, 2018; Li et al., 2010; Rinza et al., 2019), que ha demostrado un buen potencial para una adecuada gestión del riego (Gao et al., 2013; Xu et al., 2016).

La aplicación óptima del agua de riego en un cultivo está relacionada con una respuesta de apertura estomática en las hojas. Por ello, es más eficiente restringir su suministro en periodos de apertura estomática, rápida fotosíntesis y baja evaporación potencial. Estas condiciones se presentan particularmente en horas de la mañana, momento en el cual el cultivo experimenta un incremento de su temperatura interna y finalización del adormecimiento nocturno. A la temperatura de la hoja en estas condiciones se le denomina temperatura mínima de estrés hídrico foliar o temperatura húmeda (González et al., 2014; Jones, 2018). En el caso opuesto, se tiene la temperatura seca de la hoja, la cual corresponde al límite superior para la temperatura del dosel respecto a la temperatura del aire, que equivale a la temperatura de una hoja no transpirante con estomas completamente cerrados, y el cual se estima entre 5 y $10{ }^{\circ} \mathrm{C}$ sobre el valor de la temperatura del aire. Es necesario caracterizar este valor para cada cultivo y condiciones ambientales del lugar (Irmak et al., 2000; Xu et al., 2016).

Por consiguiente se obtuvieron imágenes térmicas infrarrojas del arroz cultivado bajo riego por goteo en La Molina, Perú. Seguidamente se calculó el CWSI en función de la temperatura foliar derivado de las imágenes térmicas previamente ajustadas con información de termopares, y se evaluó la relación entre el CWSI y la humedad del suelo, como método para pasar de una escala de planta (dosel) a un monitoreo de grandes áreas de cultivo para optimizar el riego y, por tanto, para una reducción en el consumo del agua.

\section{Materiales y métodos}

El estudio fue realizado en el Área Experimental de Riego de la Universidad Nacional Agraria La Molina, Perú, Provincia de Lima, localizado en La Molina (12ํㅗ 5 ;6, $9^{\circ} \mathrm{W}$ a una altitud de 244 metros), del 8 de febrero al 2 de agosto del 2017 en 12 parcelas de $15 \mathrm{~m}^{2}$ cada una (Figura 1). Como cultivo 


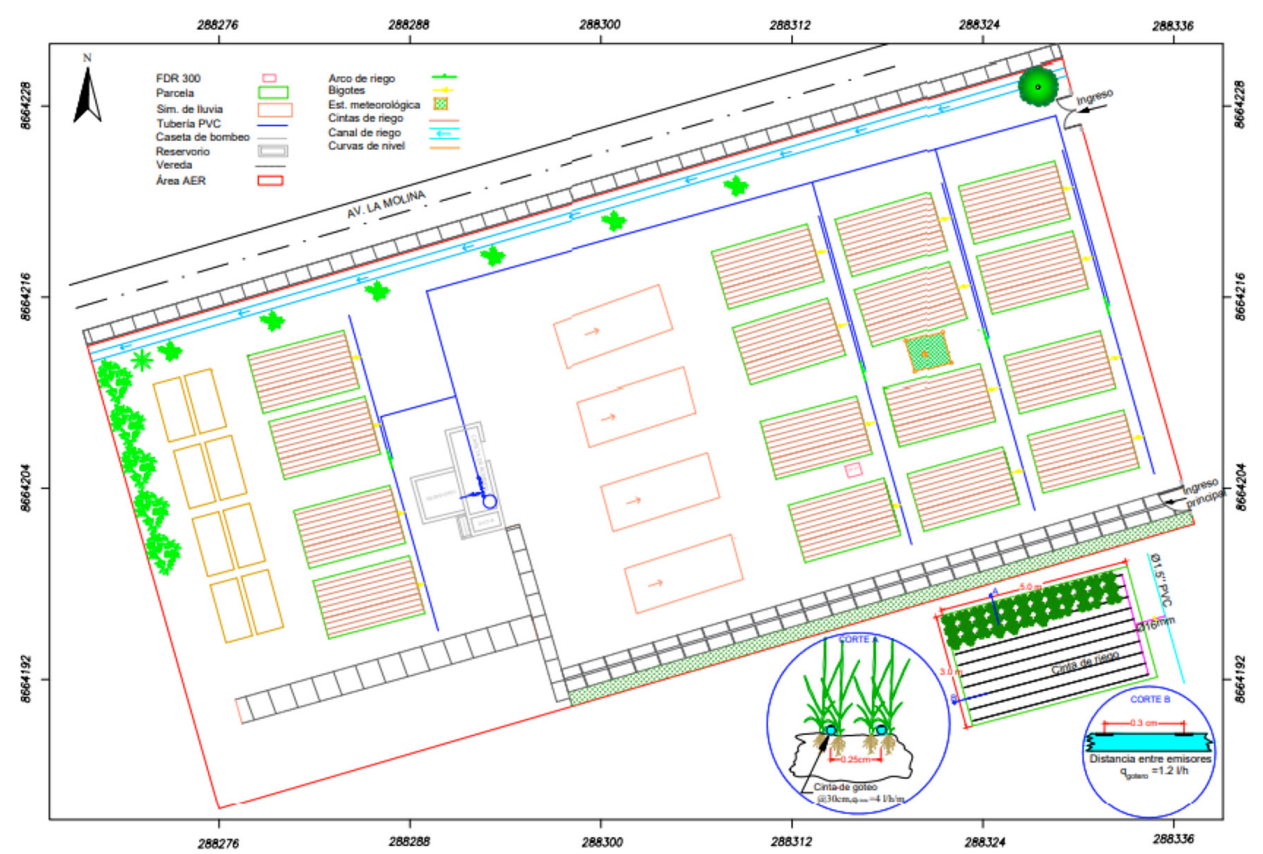

Figura 1. Plano general del Área Experimental de Riego (AER), con distribución de parcelas demostrativas y características del sistema de riego.

se empleó la variedad de arroz IR43, con siembra directa a chorro continuo, en un suelo de textura franco arenosa (47, 29 y $24 \%$ de arena, limo y arcilla, respectivamente), contenido promedio de materia orgánica, capacidad de campo, densidad aparente, $\mathrm{pH}$ y conductividad eléctrica de 2,34\%, 23,34\%, $1,5 \mathrm{~g} \mathrm{~cm}^{-3}, 7,38$ y $3,53 \mathrm{dSm}^{-1}$, respectivamente; con dosis de fertilizante aplicado de 240-60-60 y empleando un sistema de riego por goteo, con espaciamiento entre líneas y emisores de 0,25 y $0,30 \mathrm{~m}$, respectivamente, y caudal del gotero de 1,201. $\mathrm{h}^{-1}$ a una presión de trabajo de 0,5-1,0 bar.

Se colectaron imágenes térmicas e imágenes ópticas (RGB) del campo y de una superficie de referencia artificial húmeda (Jones citado por Ramírez and Monneveux, 2016) con una cámara térmica FLIR, modelo E60 (FLIR Systems Inc., Suecia), en el horario de 12:00 a 14:00 horas a una altura de 2,10 m. Se consideró la emisividad térmica igual a 0,96 , y la temperatura aparente reflejada como la temperatura estimada en una superficie de referencia, las imágenes térmicas con puntos de control previamente instalados. La temperatura del dosel se obtuvo como una medida directa, a partir de 24 sensores de termopares tipo " $t$ " (modelo TT-T-36-SLE-500, marca OMEGA) adheridos al envés de la hoja. Se colectó información cada cinco minutos con almacenamiento de datos a través de un PC200W (Campbell, EE.UU.) (Figura 2 y Figura 3), lo cual permitió el ajuste de las imágenes térmicas del dosel. El mismo colector almacenó información de temperatura y humedad del aire a una altura de $0,40 \mathrm{~m}$ del suelo, empleándose un sensor modelo CS215.

El monitoreo de la humedad del suelo se realizó con sensores de reflectometría de dominio de frecuencia (FDR, EE UU) modelo GS1 instalados a una profundidad de 0,30 y $0,15 \mathrm{~m}$, ajustados con información de humedad gravimétrica y densidad aparente (Figura 4).

Se realizó la medición directa de la temperatura del cultivo con sensores térmicos de termopares, con los cuales se caracterizó la temperatura de menor estrés hídrico o temperatura húmeda del cultivo, la cual se identifica en horas de la mañana, cuando la temperatura del aire se iguala a la temperatura del cultivo, iniciándose la apertura de estomas y transpiración de las hojas. En cambio, para la temperatura seca del cultivo se identifica en el momento del día con el mayor gradiente de temperatura entre el aire y el cultivo, que es alrededor de las 12:00 y 13:00 horas.

Para la determinación del CWSI a partir de las imágenes térmicas fue necesario primero generar 


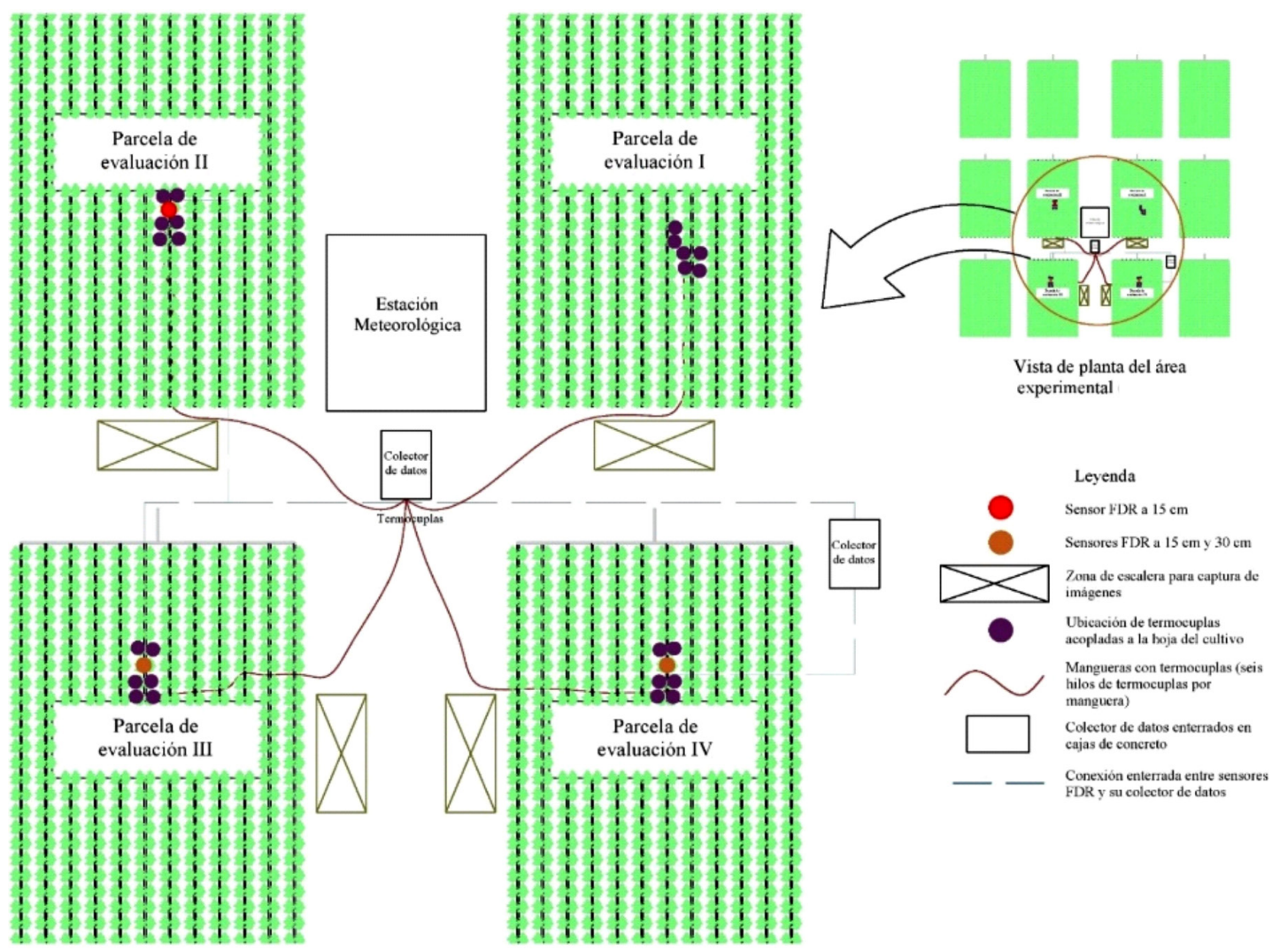

Figura 2. Esquema de distribución de parcelas en el área experimental y localización de parcelas de monitoreo y sistema de termopares.

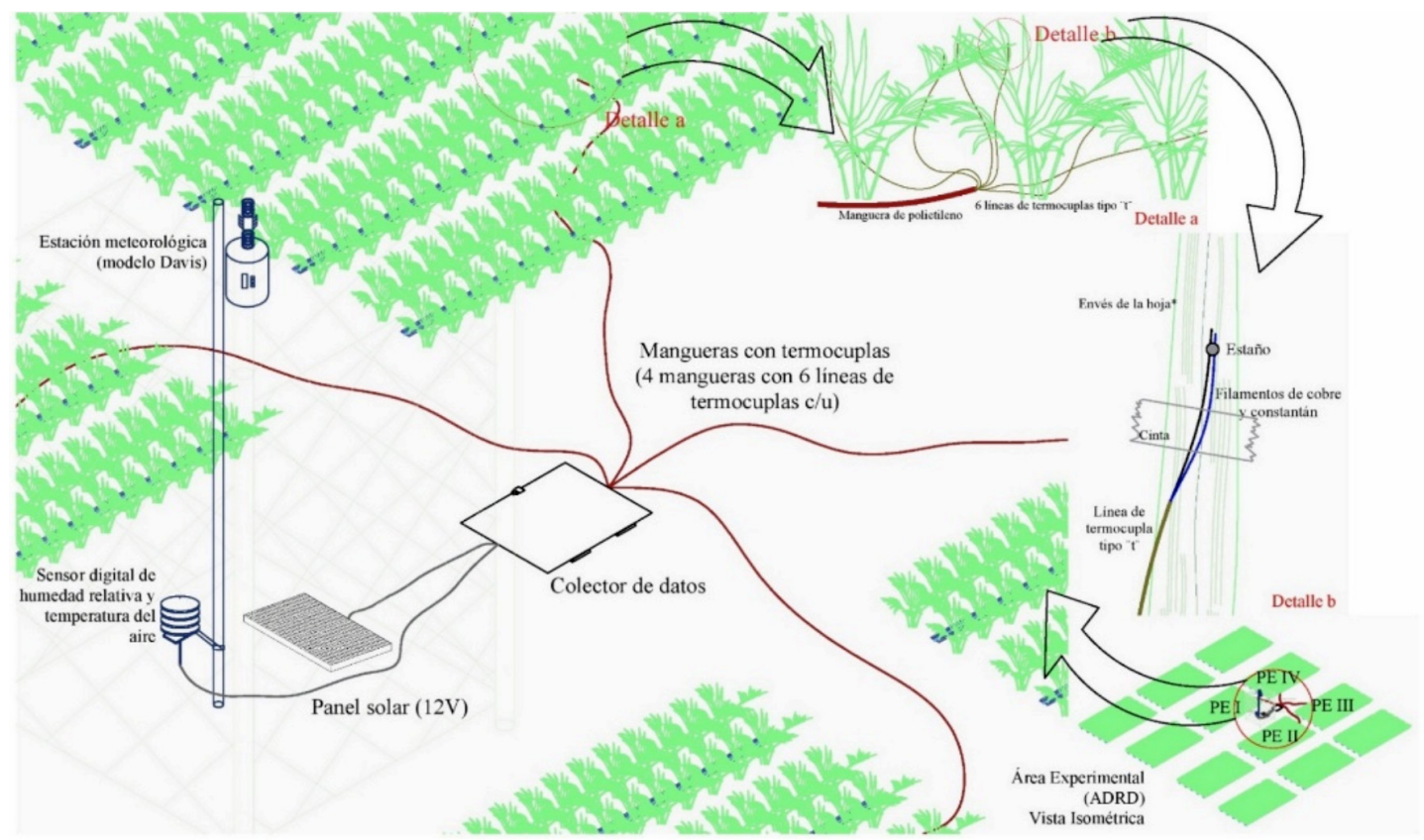

Figura 3. Distribución de 24 termopares en parcelas de monitoreo de arroz con detalle de conexión al envés de la hoja (a) y distribución en cada parcela (b). 


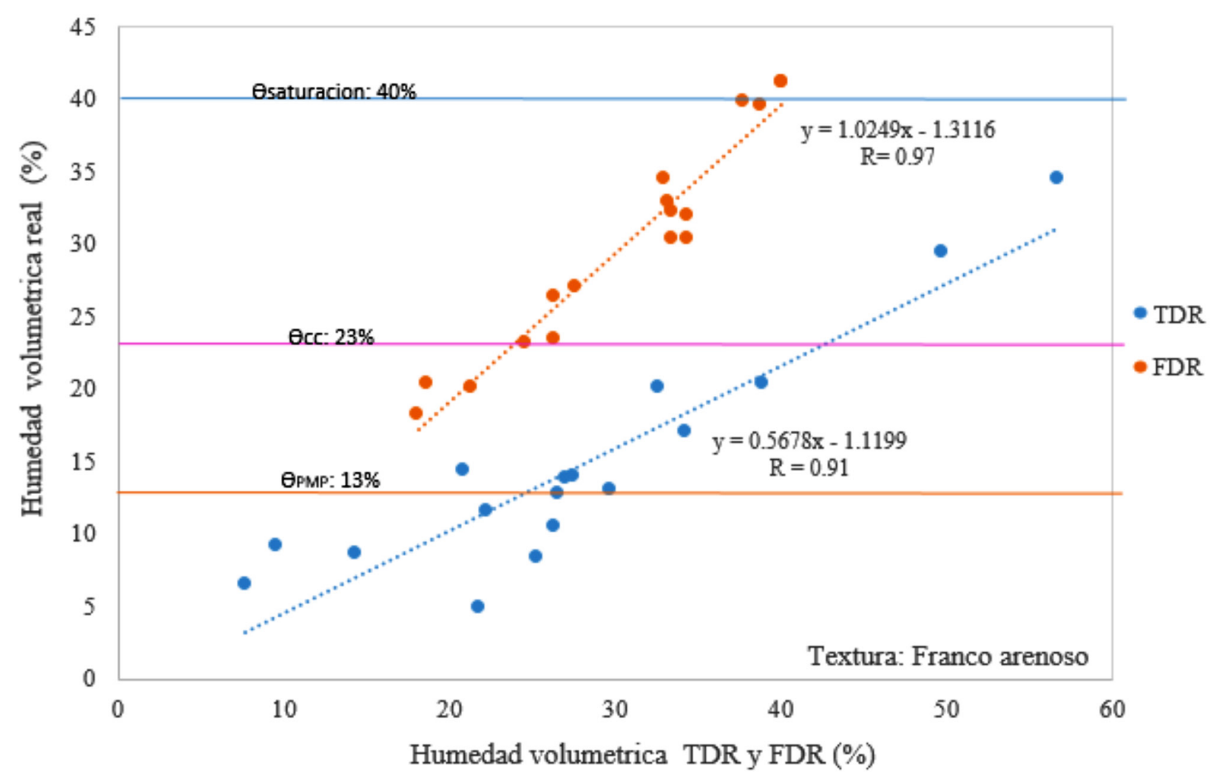

Figura 4. Relación entre la humedad volumétrica medida con sensor TDR 300, FDR (GS1) y humedad real.

una máscara de pixeles de vegetación de imágenes $\mathrm{RGB}$, a partir de la fórmula de McKinnon and Hoff (2017) $\mathrm{Z}=\mathrm{G}-0,39 * \mathrm{R}-0,61 * \mathrm{~B}$, donde $\mathrm{G}$ es la banda verde, $\mathrm{R}$ banda roja, $\mathrm{B}$, banda azul y $\mathrm{Z}$ es la cobertura vegetal. Estas máscaras permiten filtrar pixeles de cobertura vegetal mediante la superposición de imágenes RGB y térmicas (Figura 5). A continuación, con la imagen térmica recortada se procede a seleccionar el 33\% de pixeles con menores temperaturas (Meron et al., 2010). Se calcula la temperatura promedio de estos pixeles y se halla la temperatura del dosel.

Finalmente, el cálculo del índice de estrés hídrico del cultivo (CWSI) se estima según la ecuación (1), siguiendo el método propuesto por Idso citado en Rinza et al. (2019).

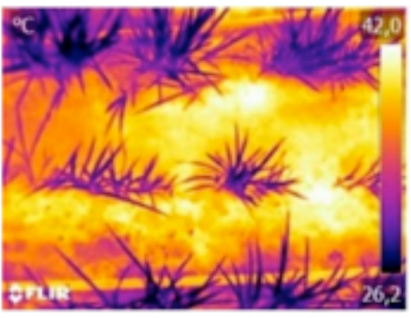

(a)

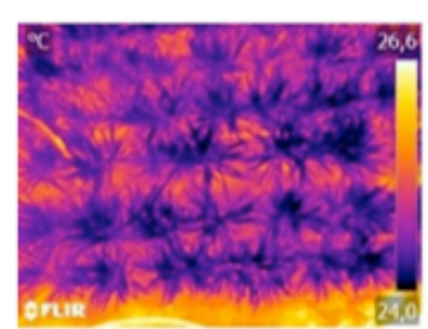

(b)

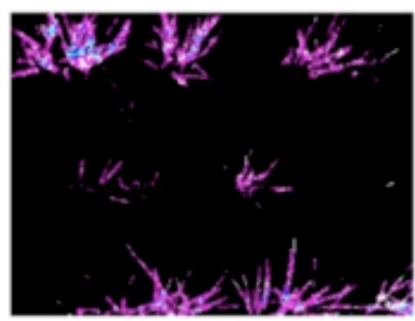

Imagen procesada (60 días)

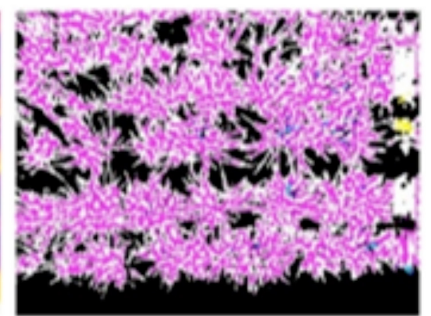

Imagen procesada (120 días)

Figura 5. Imagen térmica colectada del campo e imagen procesada del cultivo de arroz: a los 60 DDS (a) y 120 DDS (b). 


$$
\text { CWSI }=\text { Tfoliar }- \text { ThumTsec }- \text { Thum }
$$

Donde Tfoliar es la temperatura del dosel del cultivo, Thum es la temperatura húmeda (Jones, 2018) y Tsec es la temperatura seca (Xu et al., 2016).

\section{Resultados y discusión}

Durante la captación de imágenes térmicas (entre las 12:00 y 13:00 horas) se obtuvieron valores de temperatura $\left(\mathrm{C}^{\circ}\right)$ y humedad del aire $(\%)$ $(20,7 \pm 1,4,90,0 \pm 0,1)$ y $(15,8 \pm 1.0,74,7 \pm 0,1)$ para la fase reproductiva y maduración, respectivamente (Tabla 1).
En la Figura 6 se observa la temperatura promedio del aire en línea roja y en boxplot la temperatura del cultivo durante las 24 horas del día, colectadas a través de los 24 termopares. Cada boxplot representa 900 y 1500 valores de temperatura de la hoja en la fase reproductiva y de maduración, respectivamente. En la Tabla 1, la Tseca obtiene valores de 33,7 y $36^{\circ} \mathrm{C}$ según fase reproductiva y fase de maduración medidas entre las 12:00 y las 14:00 horas. La temperatura húmeda se estimó diariamente al finalizar el adormecimiento nocturno del cultivo alrededor de las 7:00 a 8:00 horas obteniéndose un valor de $15,2^{\circ} \mathrm{C}$ y $15,4^{\circ} \mathrm{C}$ para ambas fases, respectivamente.

Tabla 1. Temperatura y humedad relativa del aire, y temperatura húmeda y seca del cultivo.

\begin{tabular}{lcccc}
\hline & $\mathrm{T}$ aire $\left({ }^{\circ} \mathrm{C}\right)$ & HR aire $(\%)$ & T húmeda cultivo $\left({ }^{\circ} \mathrm{C}\right)$ & T seca cultivo $\left({ }^{\circ} \mathrm{C}\right)$ \\
\hline Fase reproductiva & $20,7 \pm 1,4$ & $90,0 \pm 0,1$ & 15,2 & 33,7 \\
Fase de maduración & $15,8 \pm 1,0$ & $74,7 \pm 0,1$ & 15,4 & 36,0 \\
\hline
\end{tabular}

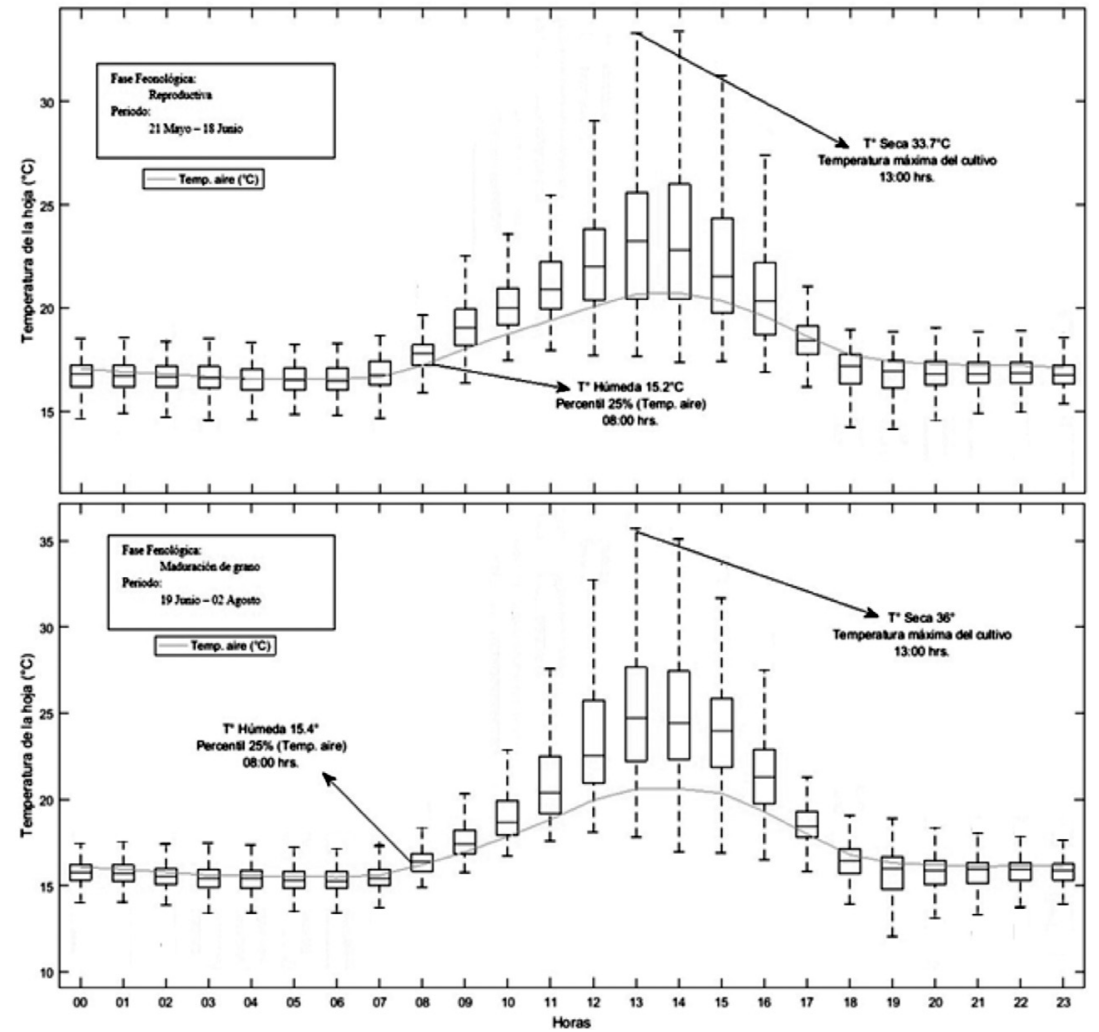

Figura 6. Variación horaria de la temperatura del cultivo de arroz medidos con termopares (box plot) y la temperatura del aire (línea amarilla) en la fase reproductiva (panel superior) y fase de maduración de grano (panel inferior). 
En la Figura 7 se muestra la variación horaria del índice de estrés hídrico del cultivo (CWSI), con valores que varían de 0,15 a 0,95 y 0,28 a 0,82 , durante la fase reproductiva y fase de maduración, respectivamente, acorde con los resultados obtenidos del monitoreo horario de temperaturas del cultivo y del aire, según González-Dugo et al. (2014). Al respecto, se observaron valores mayores de CWSI en la fase vegetativa, que correspondería a periodos de mayor estrés debido a la escasez de agua de riego por condiciones del fenómeno del Niño, además de ser un periodo crítico en el desarrollo del cultivo (Parthasarathi et al., 2018; Sandhu, Singh and Sihag, 2019); mientras que en la fase reproductiva alcanzó valores promedio menores, dado que correspondió a una etapa con riegos frecuentes programados para la recuperación del cultivo. Finalmente, en el periodo de maduración se realizaron secas intermitentes que produjeron un incremento del índice de estrés.

Se observó una correlación significativa de Pearson de 0,968, entre el CWSI obtenido con información de termopares y el CWSI alcanzado a partir de imágenes térmicas, según prueba de Tstuden para un $\alpha$ del 5\%, como se muestra en la Figura 8 , con valores mayores de CWSI en la fase

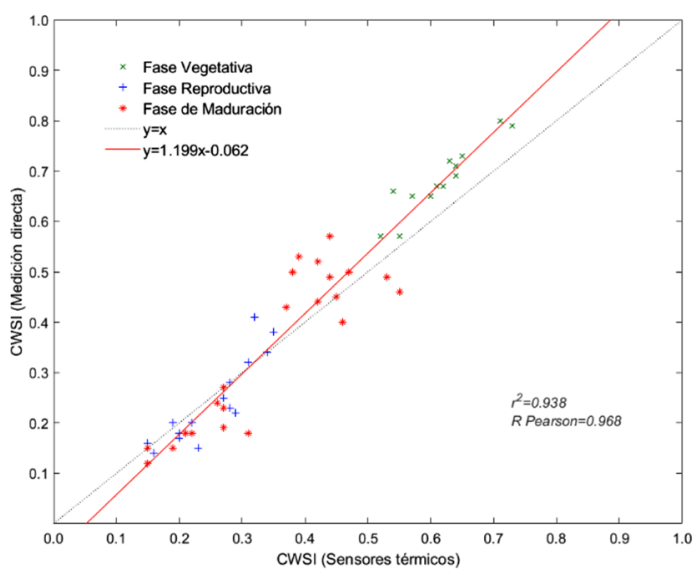

Figura 8. Relación entre el índice de estrés hídrico del cultivo (CWSI) obtenido a partir de termopares y de imágenes térmicas en las fases fenológicas del cultivo de arroz.

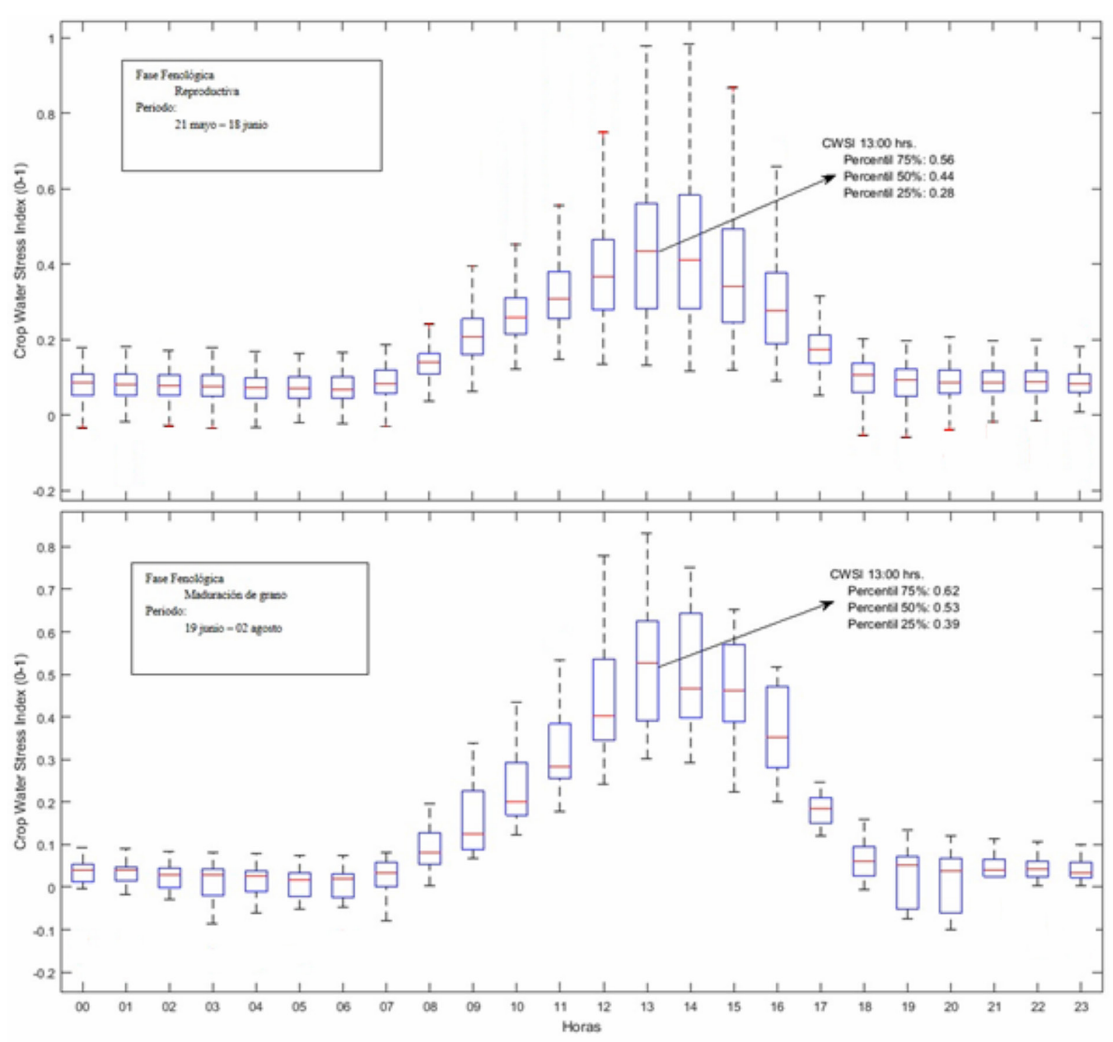

Figura 7. Variación horaria del índice de estrés hídrico del cultivo (CWSI) del cultivo de arroz en la fase reproductiva (panel superior) y fase de maduración de grano (panel inferior). 
vegetativa. En la Figura 9 se observa la correlación significativa de Pearson de $-0,522$ y $-0,375$ entre el CWSI y los valores medidos de humedad del suelo a $0,3 \mathrm{~m}$ y $0,15 \mathrm{~m}$ de profundidad, según pruebas de Tstuden para un $\alpha$ del 5\%. Los valores del CWSI variaron de 0,1 a 0,7 , con humedad del suelo entre capacidad de campo y saturación, obteniéndose un rendimiento de $1,1 \mathrm{tn}$. ha ${ }^{-1}$, con un consumo de agua de $7438 \mathrm{~m}^{3}$. ha ${ }^{-1}$ y eficiencia de uso de agua de $0,13 \mathrm{~kg}$. ha ${ }^{-1}$. El rendimiento se vio influenciado por las bajas temperaturas del aire durante el desarrollo de la panícula y floración (Figura 10), lo que ha ocasionado grano estéril $\mathrm{y}$, por consiguiente, reducción del rendimiento
(Chaudhary et al., 2003), recomendándose adelantar la fecha de siembra a noviembre.

\section{Conclusiones}

La temperatura húmeda y la temperatura seca para la variedad del cultivo de arroz IR43 en condiciones climáticas de La Molina variaron de 15,2 a 15,4 y de 33,7 a $36^{\circ} \mathrm{C}$, respectivamente, medidas en el horario de mayor transpiración para la temperatura seca (12:00 a 14:00 horas) y al finalizar el adormecimiento nocturno del cultivo para la temperatura húmeda (7:00 a 8:00 horas).

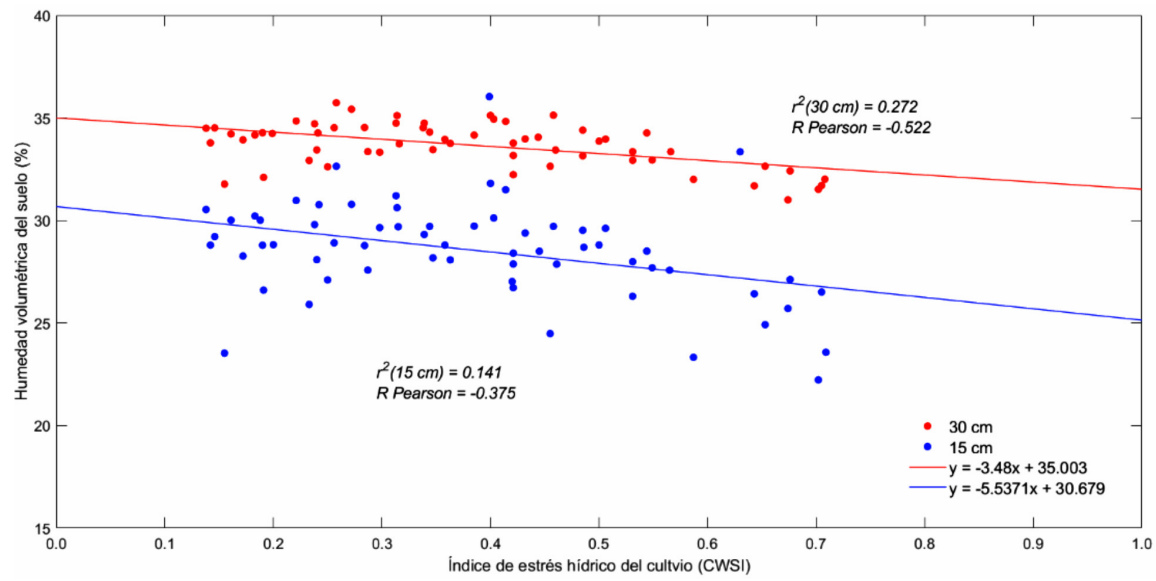

Figura 9. Relación entre el índice de estrés hídrico del cultivo (CWSI) y la humedad volumétrica del suelo a 15 y $30 \mathrm{~cm}$ de profundidad.

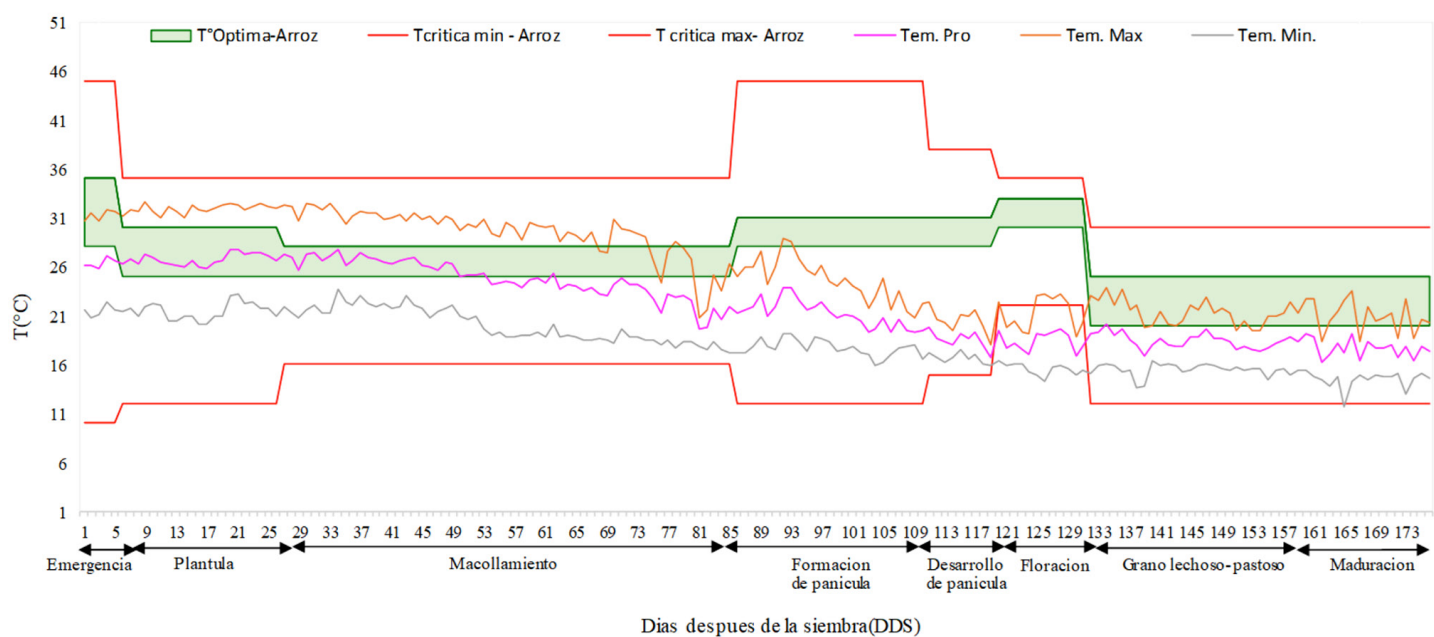

Figura 10. Variación temporal de la temperatura máxima y mínima del aire y rango de temperatura crítica y óptima en el cultivo de arroz. Periodo de cultivo: 8 de febrero al 2 de agosto del 2017 (173 DDS). 
Existe una correlación significativa entre el índice de estrés hídrico CWSI y la humedad de suelo de $-0,522$ para una profundidad $0,3 \mathrm{~m}$, lo cual indica que hay variables no medidas, que afectarían la respuesta del cultivo al variar su temperatura interna. Por ello, se recomienda incorporar el monitoreo de la conductancia estomática y el índice de área foliar, a fin de robustecer con variables fisiológicas del cultivo la estimación del CWSI, viabilizando su uso en la programación de riego.

\section{Literatura Citada}

Bellvert, J.; Zarco-Tejada, P. J.; Marsal, J.; Girona, J.; GonzálezDugo, V.; Fereres, E.

2016. Vineyard Irrigation Scheduling Based on Airborne Thermal Imagery and Water Potential Thresholds. Australian Journal of Grape and Wine Research, 22(2): 307-15.

Boonwichai, S.; Sangam S.; Mukand S., B.; Sutat W.; Avishek, D. 2019. Evaluation of Climate Change Impacts and Adaptation Strategies on Rainfed Rice Production in Songkhram River Basin, Thailand. Science of the Total Environment, 652: 189-201.

Geerts, S.; Raes, D.

2009. Deficit Irrigation as an On-Farm Strategy to Maximize Crop Water Productivity in Dry Areas. Agricultural Water Management, 96(9): 1275-84.

González-Dugo, V.; Zarco-Tejada, P.J.; Fereres, E.

2014. Applicability and Limitations of Using the Crop Water Stress Index as an Indicator of Water Deficits in Citrus Orchards. Agricultural and Forest Meteorology, 198-199: 94-104.

Han, M.; Huihui, Z.; , Kendall C. De J.; Louise H., C.; Gleason, S. 2018. Comparison of Three Crop Water Stress Index Models with Sap Flow Measurements in Maize. Agricultural Water Management, 203 (November 2017): 366-75.

Irmak, S.; Haman, D.Z.; Bastug, R.

2000. Determination of Crop Water Stress Index for Irrigation Timing and Yield Estimation of Corn. Agronomy Journal, 92(6): 1221-27.

Jones, H.G.

2018. Thermal Imaging and Infrared Sensing in Plant Ecophysiology. Advances in Plant Ecophysiology Techniques, 8: 135-151

Li, L.; Nielsen, D.C.; Yu, Q.; Ma, L.; Ahuja, L.R.

2010. Evaluating the Crop Water Stress Index and Its Correlation with Latent Heat and CO2 Fluxes over Winter Wheat and Maize in the North China Plain. Agricultural Water Management, 97(8): 1146-55.

López, R.; Arteaga, R.; Vázquez; M.; López, I.; Sánchez, I. 2009. Índice de estrés hídrico como un indicador del momento de riego en cultivos agrícolas. Agricultura Técnica en México, 35(1): 92-106.

Mekonnen, M., Mesfin, Y.; Hoekstra, A.

2016. Four Billion People Facing Severe Water Scarcity. Science Advances, 12(2): e 1500323.

Maes, W.; Steepe, K.

2012. Estimating Evapotranspiration and Drought Stress with Ground-Based Thermal Remote Sensing in Agriculture: A Review. Journal of Experimental Botany, 63(2): 695-709.

Meron, M.; Tsipris, J.; Orlov, V.; Alchanatis, V.; Cohen, Y. 2010. Crop Water Stress Mapping for Site-Specific Irrigation by Thermal Imagery and Artificial Reference Surfaces. Precision Agriculture, 11(2): 148-62.
Parthasarathi, T.; Koothan, V.; Sendass, M.; Vered, E. 2018. Evaluation of Drip Irrigation System for Water Productivity and Yield of Rice. Agronomy Journal, 110(6): 2378-89.

Pedro-Monzonís, M.; Solera, A.; Ferrer, J.; Estrela, T.; ParedesArquiola, J.

2015. A Review of Water Scarcity and Drought Indexes in Water Resources Planning and Management. Journal of Hydrology, 527: 482-93.

Poblete, T.; Ortega-Farías, S.; Ryu, R.

2018. Automatic Coregistration Algorithm to Remove Canopy Shaded Pixels in UAV-Borne Thermal Images to Improve the Estimation of Crop Water Stress Index of a Drip-Irrigated Cabernet Sauvignon Vineyard. Sensors (Switzerland), 18(2): 1-17.

Ramírez, D.A; Monneveux, P.; Quiroz, R.

2016. Mitigando los efectos de la sequía en papa: algunos alcances y eetos. In: Pino, M.T. (Ed). Estrés hídrico y térmico en papa, avances y protocolos. Instituto de Investigaciones Agropecuarias. pp. 115-129.

Rinza, J.; Ramírez, D.A.; García, J.; de Mendiburu, F.; Yactayo, W.; Barreda, C.; Velásquez, T.; Mejía, A.; Quiroz, R.

2019. Infrared Radiometry as a Tool for Early Water Deficit Detection: Insights into Its Use for Establishing Irrigation Calendars for Potatoes Under Humid Conditions. Potato Research, 62(2): 109-22.

Idso, S.B.; Jackson, R.D.; Pinter Jr., P.J.; Reginato, R.J.; Hatfield, J.L.

1981. Normalizing the Stress-Degree-Day Parameter for Environmental Variability. Agricultural Meteorology, 24: 45-55.

Sandhu, Nitika, Virender Singh, and Manvesh Kumar Sihag. 2019. Genomic Footprints Uncovering Abiotic Stress Tolerance in Rice. Vol. 2010. Elsevier Inc.

Marcelo De A., S.; Jifon, J.L.; Da Silva, J.A.G.; Sharma, V.

2007. Use of Physiological Parameters as Fast Tools to Screen for Drought Tolerance in Sugarcane. Brazilian Journal of Plant Physiology, 19(3): 193-201.

McKinnon, T.; Hoff, P.

2017. Comparing RGB-Based Vegetation Indices With NDVI For Drone Based Agricultural Sensing. RGB Vegetation Indices. Agribotix. Boulder, CO,USA. 8 p.

Xu, J.; Lv, Y.; Liu, X.; Dalson, T.; Yang, S.; Wu, J

2016. Diagnosing Crop Water Stress of Rice Using Infra-Red Thermal Imager under Water Deficit Condition. International Journal of Agriculture and Biology, 18(3): 565-72.

Abiodun, E.; Shukri, M.; Azimi, M.; Buyamina, S.; Izran, M.; Abd, M.; Okino, A; Onotub, P.; Azwan M.

2020. A review on monitoring and advanced control strategies for precision irrigation. Computers and Electronics in Agriculture. 
Gao, M.; Zhang, W.; Han, Y.; Yao, Ch.; Wang, Y.; Ding, G. 2013. A Theoretical Model Research of Rice Water Stress Index based on Automated Infrared Thermal Imaging. College of Agronomy, Shenyang Agricultural University, Shenyang, 712-715: 433-438.

Parkash, V.; Singh, S.

2020. A Review on Potential Plant-BasedWater Stress Indicators for Vegetable Crops. Sustainability, 12(10): 3945.
Weiss, M.; Jacob, F.; Duveiller, G.

2020. Remote sensing for agricultural applications: A meta-review. Remote Sensing of Environment, 236: 111402.

Chaudhary, R.; Nanda, J.; Tran, D.

2003. Guía para identificar las limitaciones de campo en la producción de arroz. Comisión Internacional del Arroz. Roma, Italia. 73 p. 